\title{
Effectiveness of State-level Pecan Promotion Programs: The Case of the Texas Pecan Checkoff Program
}

\author{
Eli D. Moore ${ }^{1}$ \\ Customer Marketing Group, Inc., 25511 Budde Road, Suite 901, The \\ Woodlands, TX 77380
}

Gary W. Williams ${ }^{2}$

Texas Agribusiness Market Research Center, Department of Agricultural

Economics, Texas A\&M University, College Station, TX 77843-2124

Marco A. Palma ${ }^{3,5}$

Department of Agricultural Economics, Texas A\&M University, 458D Blocker Building, 2124 TAMU, College Station, TX 77843-2124

\section{Leonardo Lombardini ${ }^{4}$ \\ Department of Horticultural Sciences, Texas A\&M University, College Station, TX 77843-2133}

Additional index words. advertising, evaluation, benefit-cost analysis, marketing order, checkoff

\begin{abstract}
The Texas Pecan Board was established in 1998 to administer the Texas Pecan Checkoff Program and is financed through a half cent per pound assessment on grower pecan sales. The Board spends the assessment collections on a variety of advertising campaigns in an attempt to expand demand for Texas pecans and to increase the welfare of Texas pecan growers. This article presents an evaluation of the economic effectiveness of the Texas Pecan Checkoff Program in expanding sales of Texas pecans. First, the effects of Texas Pecan Board promotion on sales of all Texas pecans are determined using the ordinary least squares estimator followed by a test for differential effects of Texas Pecan Board promotion activities on sales of improved and native Texas pecan varieties using the seemingly unrelated regression estimator. The analysis indicates that the Texas Pecan Checkoff Program has effectively increased sales of improved varieties of Texas pecans but has had no statistically measurable impact on sales of native varieties of Texas pecans. A benefit-cost analysis determines that $\$ 35.0$ in additional sales revenues are generated for every dollar invested in promotion, indicating that the Texas pecan promotion program has been financially successful. The per unit return is large but on a very few dollars available for investment in promotion implying the need for more investment for more meaningful returns.
\end{abstract}

The pecan [Carya illinoinensis (Wangenh.) C. Koch] is unique among U.S. nut crops. Besides being the only native nut grown on a commercial scale, pecans exhibit alternate bearing behavior, often referred to as biennial bearing, which leads to wide biennial fluctuations in production and in nut quality characteristics at the orchard, regional, and national levels. This annual instability of supply and quality causes major problems for developing and maintaining demand within domestic and foreign markets. Perhaps for that reason, pecan is also the only U.S. nut industry with no national-level generic promotion program. National generic promotion ("checkoff") pro-

Received for publication 25 June 2009. Accepted for publication 29 Aug. 2009.

${ }^{1}$ Project Manager.

${ }^{2}$ Professor and Director.

${ }^{3}$ Assistant Professor and Extension Economist.

${ }^{4}$ Assistant Professor.

${ }^{5}$ To whom reprint requests should be addressed; e-mailmapalma@tamu.edu. grams are viewed as farmer self-help activities requiring minimal federal involvement or funding. They have been authorized by Congress for various farm commodities over the years as federally sanctioned, mandatory national programs, or as components of federal marketing order programs. Peanuts are one of 18 U.S. farm commodities with a federally legislated national generic promotion program, known as the Peanut Promotion, Research, and Information Order under the Commodity Promotion, Research, and Information Act of 1996 (7 U.S.C. 7411-7425). National generic promotion programs are authorized for almonds, hazelnuts, and walnuts through their respective federal marketing orders. The U.S. Department of Agriculture's Agricultural Marketing Service has some administrative and oversight responsibilities for these programs, but they are administered by boards of growers, shellers, handlers, and other industry representatives (Becker, 2004).

Implemented in 1992, the Pecan Promotion and Research Act of 1990 established a Pecan Marketing Board to carry out a coordinated national program of research and promotion to strengthen the pecan industry's domestic and foreign market position. However, 2 years later, in a referendum required by the Act, the program was terminated with $62 \%$ of those voting in the referendum against continuance of the program. Since then, efforts to promote sales of pecans have been piecemeal through independently operated promotion programs established by the National Pecan Shellers Association (NPSA) and all pecan-producing states. Typical of state-level pecan promotion programs is the Texas Pecan Checkoff Program established under the Texas Commodity Referendum Law (Texas Agricultural Code Chapter 41) in Aug. 1998 and administered by the Texas Pecan Board (TPB). The law authorizes TPB to promote pecans in an attempt to increase the welfare of Texas pecan growers.

This article addresses the general question of the effectiveness of state-level efforts to promote pecans. Specifically, the article examines whether or not the Texas Pecan Checkoff Program has worked as intended to increase sales of Texas pecans. The analysis focuses on the answers to three key questions: 1) What have been the effects of the Texas Pecan Promotion Program on sales of Texas pecans? 2) Is the level of effectiveness related to pecan variety (native versus improved varieties)? 3) What has been the return on investment made by Texas pecan growers from the promotion of sales of Texas pecans? Conclusions and implications for state-level pecan promotion programs are drawn from the analysis of these three questions.

\section{Background}

The United States is by far the world's largest pecan grower accounting for more than $80 \%$ of the world's supply (Onunkwo and Epperson, 2000). The U.S. pecan industry functions in a market relatively free of government intervention and supplies a perishable, perennial commodity with a natural tendency for yields to fluctuate widely from year to year. The alternate bearing nature of the pecan tends to create a pattern of high production in 1 year followed by low production in the next, often referred to as the "on" and "off" years. Thus, pecan prices are sensitive to changes in supply and demand with low supplies in the "off" years often resulting in higher prices than in the "on" years (Shafer, 1996). Pecans cannot be stored without refrigeration for long periods of time in anticipation of future prices as a result of their susceptibility to oxidation (Florkowski and $\mathrm{Wu}, 1990$ ).

The U.S. and Texas pecan industries. Experiencing considerable growth during much of the early to mid-20th century, U.S. pecan production and the industry it supports have shown little sustained expansion since at least the 1970s. Average annual U.S. pecan production dropped from 117.5 million pounds (shelled basis) in the 1980s to only 111.9 million pounds in the 1990 s and then 
back to 117.0 million pounds since $2001 / 02$. Wood et al. (1994) argue that growth stalled because the industry failed to invest adequately in market development and expansion. Florkowski and Park (2001) lay out strategies for expanding pecan demand through advertising and marketing campaigns and conclude that such programs can have a statistically significant, positive effect on consumption when the promotion targets pecan uses, pecan visibility, and the health benefits of pecans such as its effect on decreasing low-density lipoprotein cholesterol levels as discussed by Rajaram et al. (2001).

There are hundreds of pecan varieties throughout the world, classified as either native or improved varieties (Thompson and Young, 1985). Trees that have not been grafted or budded are referred to as native or seedling. Improved varieties are those that have been genetically altered through selection and controlled crossing to yield desirable characteristics such as high kernel percentage (high meat content), low yield variations, and resistance to diseases and insects (Worley, 1994). Improved varieties sell at a premium price compared with native varieties because they are perceived as higher quality products. Quality tends to be a major factor in the price differentiation of improved and native pecan varieties (Park and Florkowski, 1999).

Quality issues have been central to the development of the pecan industry (Wood et al., 1994). The quality of pecans is a function of certain physical characteristics and different segments of the industry emphasize different characteristics (Erickson, 1994). The characteristics of pecans that are often associated with quality are meat yield, color, size, minimal foreign material, and shell-out ratio (meat to shell weight ratio). The shell-out ratio, calculated as the weight of the kernel or meat divided by the weight of the entire nut, has empirically proven to have the most significant impact on pecan prices (Florkowski and Hubbard, 1994).

Pecans are grown in 14 states throughout the southern United States from California to Florida. Marketing and harvesting seasons vary widely. Texas harvests pecans earlier than any other state in the country and has the longest marketing season. Texas has been successful in producing pecans primarily because of the numerous east Texas rivers that provide transportation and irrigation for pecan growers (Wood et al., 1994). Although pecans are now grown statewide in Texas, the principal producing counties are Comanche, El Paso, and San Saba. California has the shortest harvesting season and Arizona is last to harvest its pecans. Texas recently dropped to third place in production after vying for several years with New Mexico for the second spot behind Georgia. Together, the three states accounted for $76 \%$ of total U.S. pecan production in 2007 with Texas alone accounting for $18 \%$ (Fig. 1). Although overall pecan production has shown little trend in recent years, the share of total production composed of improved varieties has increased from an average of $\approx 65 \%$ in the 1980 s to an average of over $75 \%$ since 2000 [U.S. Department of Agriculture (USDA), 2008b].

The Texas Pecan Checkoff Program. Texas pecan promotion programs are financed through an assessment ("checkoff") on pecan sales from growers to first handlers. Under the Texas Pecan Checkoff Program, growers with 500 pecan trees or more and at least 15 acres are required to pay the assessment and are referred to as "qualified growers." All qualified growers are required to pay the checkoff assessment of a half cent per pound of in-shell pecans sold or transferred to a processor or pool. The first party to purchase the pecans from the grower is referred to as the first handler and includes shellers, brokers, processors, accumulators, and growers who market their own pecans.

The assessment is due when the pecans are first processed or shelled. Because the checkoff program is mandatory, the first handler is required by law to collect the assessment from the grower and then report and submit it to the Texas Pecan Board. However, there is little to no enforcement of the collection requirement as a result of a lack of funds and manpower at the Texas Department of Agriculture. Consequently, only $\approx 44 \%$ of the available funds are collected on average each year, which effectively limits the potential impact of the Texas Pecan Checkoff Program and suggests that there may be a free rider problem (Adams, 2007).

Total annual checkoff collections are quite small, varying from a low of $\$ 85,500$ in 2005-2006 to a high of $\$ 167,600$ in 19992000. TPB spends the annual checkoff collections on promotional activities in seven different categories, including: 1) the ambassador program (costs of a state pecan representative); 2) festivals and conferences; 3) clipping service; 4) research (primarily related to the health benefits of pecans); 5) a web site; 6) media; and 7) miscellaneous promotion activities (Fig. 2). The media category is the largest expense category, accounting for $60 \%$ of total promotion expenses and includes radio advertisements, promotional videos, magazine articles and advertisements, recipe booklets, posters, other publications, and more.

\section{Materials and Methods}

Measuring the effects of promotion on the sales of Texas pecans is simple in concept. Promotion is intended to increase the demand for Texas pecans as illustrated in Figure 3. If successful, the consequence is a rightward shift in the demand for Texas pecans, resulting in an increase in quantity of pecan sales from $\mathrm{Q}_{0}$ to $\mathrm{Q}_{\mathrm{N}}$. All that the analyst needs to do, then, is to measure the

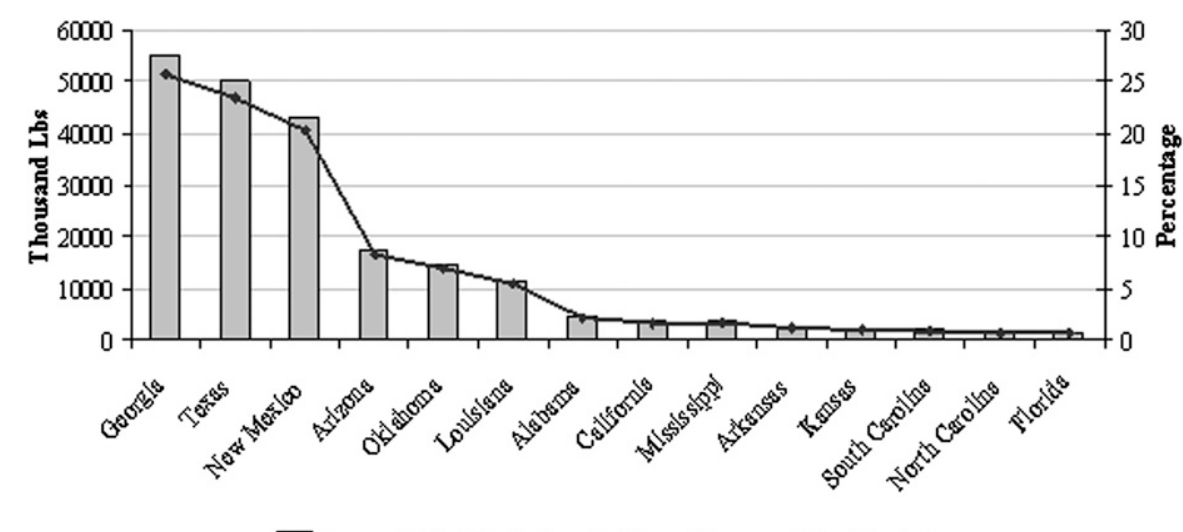

$\square$ Average Utilind Production $\rightarrow$-Share of Average Utilined Prochution

Fig. 1. Average used production and share of used production by state, 2002-2003 to 2004-2005.

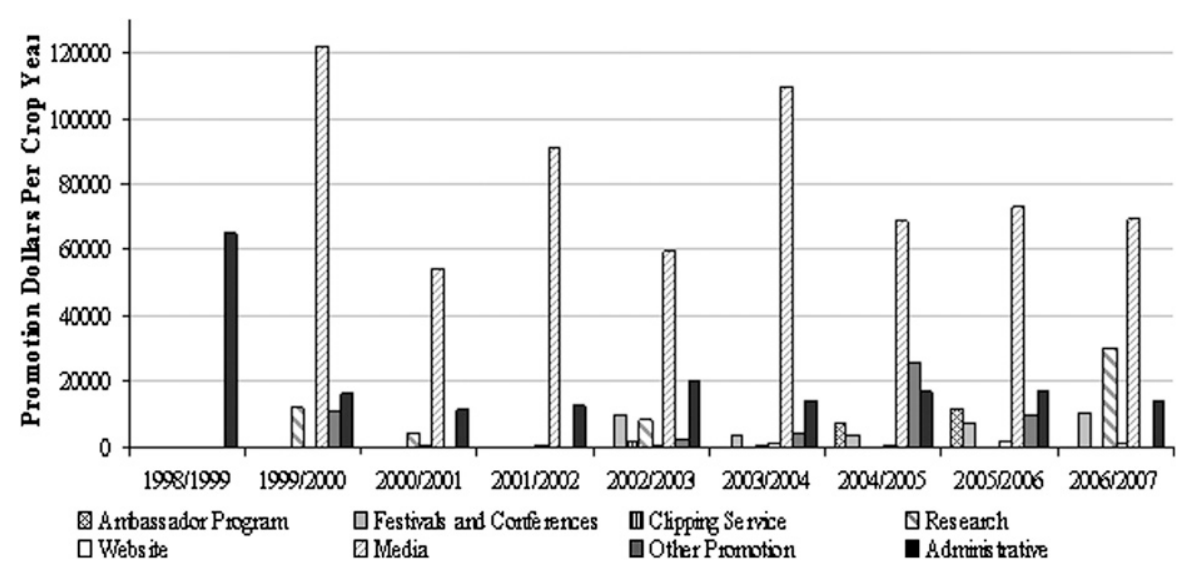

Fig. 2. Texas Pecan Board Expenditures by category, 1998-1999 to 2006-2007. 


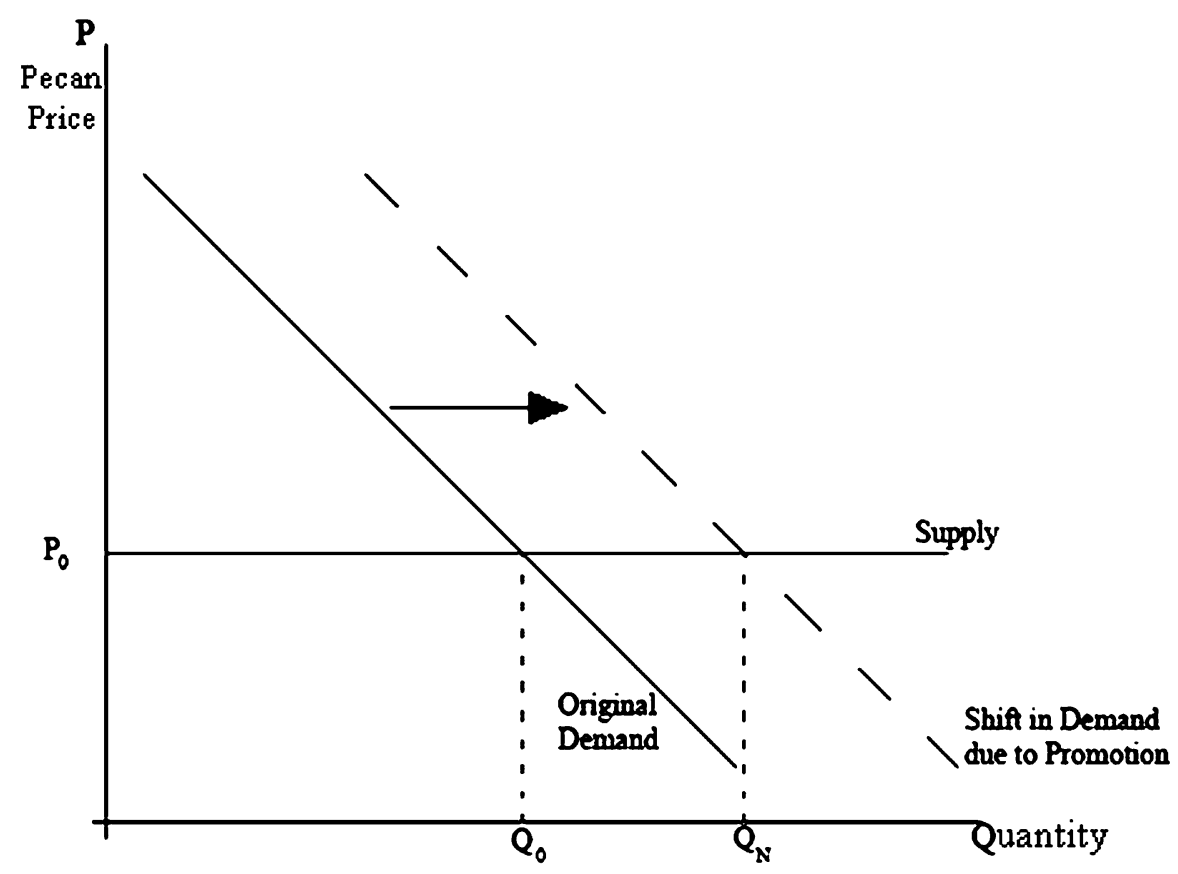

Fig. 3. Illustration of the shift in demand for Texas pecans as a result of promotion.

increase in sales as a result of the promotion. However, measuring the actual magnitude of any shift in the demand for Texas pecans that can reliably be attributed exclusively to the promotional efforts funded by the Texas Pecan Checkoff Program is a good deal more complicated.

Early efforts to measure the demand effects of promotion programs relied largely on anecdotal evidence and simple comparisons of gross investments in promotion and gross changes in sales. During periods of rapidly expanding markets and rising prices, this approach tends to yield some persuasive stories and even more impressive upwardsloping graphical relationships between promotion expenditures and sales. The problem with this approach, however, is that various factors other than the promotion program affect the volume and value of commodity sales such as relative price changes, agricultural policies, changes in incomes, population growth, competition from other products, and consumer health concerns and demographics, just to name a few.

Increasingly sophisticated statistical methods have been developed to isolate and measure the unique contribution of promotion programs to the performance of the sales of the commodity being promoted. Most common have been econometric regression techniques and models to statistically disentangle the effects of promotion program activities on commodity sales and demand from those of other market forces. The process usually requires a large amount of historical data on sales of the product and advertising expenditures over time as well as many other relevant market forces that might have affected sales over the same period. The application of the statistical technique to the data allows for measurements of the unique contribution of each market force considered,

ciation to promote exports cans over the 11-year period of 1986 to 1996 using Market Promotion Program and Targeted Export Assistance Program funds provided by the USDA. They conclude that pecan promotion expenditures had a statistically significant, positive effect on U.S. pecan exports during that period. They calculate a pecan export BCR of $\$ 6.45$ per promotion dollar spent in Asia and $\$ 6.75$ per dollar spent in the European Union.

Florkowski and Park (2001) develop a generalized Heckman model of pecan purchase decisions that they apply to the results of a nationwide mail survey focused on the demand for raw, unprocessed pecans in 1993 to determine factors that influence pecan consumer purchasing decisions. The results are used to discuss alterative promotional and marketing strategies with particular reference to the promotional efforts of the NPSA but do not provide a measure of effectiveness of past pecan promotional ac- tivities or a measure of the benefit of promotion to those who pay the costs.

Florkowski et al. (1992) analyzed the effects of promotion programs for other tree nuts and concluded that those programs have decreased the market share of pecans. Almond promotion programs, primarily in California, have been studied by Alston et al. (1995), Bushnell and King (1986), Crespi and Sexton (2001), Halliburton and Henneberry (1995), and Kinnucan and Christian (1997), among others. In general, they find that promotion has effectively generated demand for almonds.

Data used in this study include pecan sales, prices of pecans, almonds, and walnuts from the USDA (2008b); promotion expenditures provided by the Texas Pecan Board; total pecan bearing acreage used to compute pecan yield for total, improved, and native pecans as a proxy for availability from the USDA (USDA, 2008a); and consumer price index, disposable income, and population statistics from the Bureau of Economic Analysis for 1971-1972 through 2006-2007 (U.S. Department of Commerce, 2008).

Using these data, three econometric models were developed to analyze the effects of Texas Pecan Board promotion expenditures on: 1) Texas sales of improved and native varieties combined (Model 1); 2) Texas sales of only improved varieties of pecans (Model 2 ); and 3) Texas sales of only native and seedling varieties of pecans (Model 3 ).

Model 1 (aggregate model for all sales of Texas pecans) hypothesizes that annual sales of all Texas pecans $\left(\mathrm{Y}^{\mathrm{P}}\right)$ are determined by the inflation-adjusted prices of all pecans $\left(\mathrm{PR}^{\mathrm{P}}\right)$, almonds $\left(\mathrm{PR}^{\mathrm{A}}\right)$, and walnuts $\left(\mathrm{PR}^{\mathrm{W}}\right)$; the availability of pecans for sale (AV), inflation-adjusted consumer disposable income (DIR), an indicator variable representing a structural change in consumer preference from native to improved pecans over time (STRUC), and TPB inflation-adjusted promotion expenditures (PROMR). The general Model 1 equation is written as:

$$
\begin{aligned}
Y^{p}= & f\left(P R^{P}, P R^{A}, P R^{W}, \sqrt{P R O M R_{t-j}},\right. \\
& \text { DIR }, A V, S T R U C)
\end{aligned}
$$

The parameters of Eq. (1) were estimated using the ordinary least squares (OLS) estimator assuming a linear in logs (constant elasticity) structural form as is common with many checkoff promotion programs studies, a point also noted by Rusmevichientong and Kaiser (2009). Because the promotion data included zeroes as data points in the years before the establishment of the Texas Pecan Checkoff Program (1971-7272 to 19981999), the natural logarithm of PROMR could not be calculated over the full time period of analysis (1971-1972 to 2006-2007). Consequently, to maintain a diminishing marginal returns relationship between PROMR and pecan sales $\left(\mathrm{Y}^{\mathrm{P}}\right)$ in Eq. (1), a square root transformation of the promotion data was used to represent promotion expenditures following Williams et al. (2008).

Because the effect of expenditures on promotion in a given period may affect 
consumer decisions over a longer period of time (referred to as the "carryover effect" of advertising), the promotion data are introduced into the model using a lag structure. We test for lag formulation and lag length using three commonly used, alternative lag models: 1) the polynomial distributed lag (PDL) formulation (Almon, 1965); 2) a geometric lag; and 3) simple lags of varying lengths. The search for the pattern and time period over which pecan advertising and promotion affect Texas pecan sales involved a series of nested OLS regressions. There were limitations on the number of lags and the degree of lag that could be used because the data were on a crop year (12-month) basis and the TPB has only been promoting pecans since 1999-2000. For each lag formulation, lags of up to 4 years were considered and for the PDL, up to fourth-degree polynomials were considered with alternative choices of head and tail restrictions. Based on the Akaike Information Criterion (AIC), the Schwarz Information Criterion (SIC) statistic, and the Hannan-Quinn criterion, a single, nonweighted lag of promotion was used.

The TPB pecan promotion strategy has been to target household consumption of pecans through festivals and conferences, media advertisements, recipes at grocery stores, and so on. Typically, pecans purchased by households are improved varieties, whereas native varieties are typically used in the production of candies, baking goods, and other processed food products (Worley, 1994). Consequently, TPB may have inadvertently targeted consumption of improved pecans by targeting household consumption of pecans. Thus, we test the hypothesis that TPB promotion has had a greater impact on sales of improved varieties than on native pecans by separating sales by variety (improved versus native) and estimating two separate pecan sales models. Models 2 and 3 represent Texas sales of improved pecan varieties $\left(\mathrm{Y}^{\mathrm{i}}\right)$ and native varieties $\left(\mathrm{Y}^{\mathrm{n}}\right)$, respectively, and are given as:

$$
\begin{aligned}
Y_{t}^{i}= & f\left(P R_{t}^{i}, P R_{t}^{A}, P R_{t}^{W}, \sqrt{\operatorname{PROMR}_{t-j}},\right. \\
& \left.Y_{t-1}^{i}, A V_{t}, S T R U C_{t}, A D_{t}, D R_{t}\right)
\end{aligned}
$$

$$
\begin{aligned}
Y_{t}^{n}= & f\left(P R_{t}^{n}, P R_{t}^{A}, P R_{t}^{W}, \sqrt{P R O M R_{t-j}}\right. \\
& \left.Y_{t-1}^{n}, A V_{t}, D I R_{t}\right)
\end{aligned}
$$

where $A D$ is a binary variable representing a change in production from 2001 to 2002 that was the largest nominal variation in sales from an "on" year to an "off" year for improved varieties and all other variables are as defined earlier (see Eq. 1), the superscript $i$ denotes improved variety-specific variables, the superscript $n$ represents nativespecific variables, $j$ is the number of lags of the promotion variable, and $t$ designates year. The time period of analysis continues to be 1971-1972 to 2006-2007.

Note that the specification of Models 2 and 3 includes the same variables as Model 1 with some additions. Most notably, lagged dependent variables are included in the models to capture potential habit persistence or dynamic response of consumers to changes in market signals. Habit persistence suggests that as price changes, consumers spread their response over some period of time instead of changing their demand immediately because of their habit or tendency to continue purchasing a particular commodity (such as native pecans) even when other forces such as the availability of a new or improved products (improved variety pecans) provide an incentive to change buying behavior. Habit persistence is not relevant for the aggregate pecan sales demand (Model 1) because native and improved pecan sales are added together. As consumers switch their consumption of pecans from native to improved varieties, the dynamic effects of decreasing sales of native pecans combined with increasing sales of improved pecans creates an offsetting effect in the aggregate model.

For estimating the parameters of Models 2 and 3, the relationship among the variables in each model is assumed to be linear in logarithms as is the case for Model 1. Given the high correlation found between native and improved pecan prices, we tested for the presence of multicollinearity between the two price series using the variance inflation factor (VIF) test. The test failed to reject the null hypothesis that multicollinearity is present at a critical value of VIF $=5$ with VIF statistics of 11.39 and 9.88 for improved and native pecan prices, respectively. Therefore, to avoid statistical issues associated with multicollinearity, only the price of improved pecans was included in the improved pecan sales model (Eq. 2), whereas only the price of native pecans was included in the native pecan sales model (Eq. 3).

To account for potential carryover effects of promotion in each equation as was done for Model 1, we again tested for lag formulation and lag length using the same three alternative lag models (PDL, geometric, and simple, unweighted lags). Again, based on the AIC and SIC statistics as well as the Hannan-Quinn criterion, a single, nonweighted lag of promotion was used for Models 2 and 3 as was the case for Model 1 .

The parameters of the Models 2 and 3 were estimated together using the seemingly unrelated regression (SUR) estimator. Models 2 and 3 are conceptually related in that they are demand equations for closely related commodities with similar variables. When estimating the parameters of such equations, there is a potential for their error terms to be correlated (Pindyck and Rubinfeld, 1998). In this case, the use of the OLS estimator as is done for Model 1 for all pecan sales could lead to inefficient parameter estimates for Models 2 and 3. The SUR estimator is a more appropriate technique for addressing crossequation error correlation and results in more efficient parameter estimates. If the disturbances or error terms of these two models are unrelated, then there is no relationship between the two models and the empirical results will be the same as estimating the parameters of the two models separately using the OLS estimator assuming that each variable has the same number of data points.

To measure the cost-effectiveness of the TPB pecan promotion program in increasing sales of Texas pecans, results of the statistical analysis were used to calculate the BCR associated with the program, including a net revenue BCR (NBCR), a discounted BCR (DBCR), and a sales BCR (SBCR) following the procedures outlined by Williams et al. (2008). The NBCR is simply the net additional revenues generated by promotion per dollar spent on promotion and is calculated as the ratio of total gross additional revenues generated by the promotion program $(\mathrm{R})$ net of promotion costs to total promotion expenditures (PROM) over time. The DBCR discounts the additional net revenue $\left(R_{t}-\right.$ $\mathrm{PROM}_{\mathrm{t}}$ ) generated over time to account for the time value of money before dividing by the promotion dollars spent. In calculating the DBCR, we follow Williams (1999) and use the 30-day U.S. Treasury bill (T-bill) rate because it represents a conservative, alternative investment for commodity checkoff groups like the Texas Pecan Board. The SBCR provides a measure of the additional quantity sold (in pounds) as a result of the promotion programs per dollar spent on promotion.

\section{Statistical Results}

The results of estimating the parameters of Model 1 indicate clearly that promotion expenditures by the TPB have had a statistically significant, albeit lagged effect on the sales of Texas pecans measured in the aggregate for both native and improved varieties (Table 1). The $P$ value for the promotion variable is 0.0051 implying that promotion is significant at the $99 \%$ level. The short-run promotion elasticity of Texas pecan sales over the period of analysis $\left(e^{P R O M}\right)$ is calculated using the estimated parameter $\left(\lambda^{P R O M}\right)$ of the square root of lagged promotion $\left(\sqrt{\text { RROMR }_{t-1}}\right)$ in Model 1 as follows:

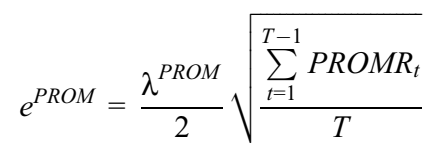

where $\mathrm{T}$ is the total number of years (19711972 to 2006-2007).

Note in Eq. (4) that real promotion expenditures are summed only through the next to last year of the period of analysis because the effects of promotion on sales were found to be lagged one period. Using Eq. (4), the promotion elasticity $\left(e^{P R O M}\right)$ was calculated to be 0.03114 , meaning that doubling promotion expenditures (a 100\% increase) would lead to a $3.1 \%$ increase in pecan sales, which is consistent with the calculated promotion elasticities reported for other commodity promotion programs (see Williams et al., 2008). This result is consistent with the conclusions over a broad range of research on commodity checkoff programs that the response of sales to checkoff promotion expenditures (the promotion elasticity) is small and usually in 
the range between close to zero and 0.10 . Reported promotion elasticities have ranged from as low as 0.0018 for U.S. fluid milk sales (Kinnucan et al., 2001) to 0.127 for orange juice (Williams et al., 2004).

The results of estimating the other parameters of Model 1 in Table 1 are consistent with theoretical expectations. The statistically significant and positive estimated coefficient of the indicator variable STRUC suggests that the transition of the industry from native to improved pecans has tended to boost total sales of Texas pecans over the years. Although the price of pecans is found to be a statistically significant determinant of Texas pecan sales, the estimated price coefficient of -0.0019 indicates a highly inelastic response of pecan sales to changes in price. Combined with an estimated availability (AV) elasticity of 0.9847 , the low estimated price elasticity implies that Texas pecan sales are much more responsive to changes in the availability of pecans from year to year than to changes in price.

The highly price-inelastic demand for pecans (that is, the unresponsiveness of demand to changes in price) may also suggest that combining native and improved varieties into a single, aggregate sales equation creates statistical problems. Although improved and native varieties are substitutes, using a weighted average of the prices of the two varieties in the aggregate sales equation (Model 1) forces native and improved varieties to behave as complements. Thus, for example, increases in the price of improved pecans should decrease sales of improved pecans but increase the sales of native pecans. However, as a component of an aggregate weighted pecan price, an increase in the price of improved pecans increases the weighted average price and reduces sales for all pecans, both native and improved. This offsetting effect may result in the highly priceinelastic estimated effect of the weighted average price on aggregate sales of pecans.

To resolve this problem, Eq. (1) was disaggregated into separate sales equations (Models 2 and 3) for improved and native pecans. The parameters of the two equations were then jointly estimated using the SUR estimator (Table 2). For the demand for improved pecan varieties, the own-price $\left(\mathrm{PR}^{\mathrm{i}}\right)$ was found to be statistically significant. Such was not the case for the demand for native pecans, however, for which the estimated coefficient for the own-price $\left(\mathrm{PR}^{\mathrm{n}}\right)$ was not statistically significant. The estimated short-run own-price elasticity of improved pecan variety sales is -0.3231 with a longrun elasticity of -0.5320 .

The statistical insignificance of the real price of native pecans $\left(\mathrm{PR}^{\mathrm{n}}\right)$ in Model 3 does not necessarily mean that consumers do not consider price when making their native pecan-purchasing decisions. Rather, results suggest that changes in price do not result in large changes in purchases of native pecans and that purchases are more sensitive to changes in other variables such as the availability of pecans for sale than to changes in price.

Table 1. Model 1: ordinary least squares results using an autoregressive error correction model. ${ }^{2}$

\begin{tabular}{|c|c|c|c|c|c|}
\hline \multicolumn{6}{|c|}{ Dependent variable - $\ln (Y)$ (natural $\log$ of all Texas pecan sales) } \\
\hline & Lag & Coefficient & SE & t value & \\
\hline & 1 & -0.466418 & 0.164259 & -2.84 & \\
\hline & & Yule-Walker estimates & & & \\
\hline & SSE & 0.16570295 & DFE & 29 & \\
\hline & MSE & 0.00468 & Root MSE & 0.06841 & \\
\hline & $\mathrm{SBC}$ & -73.439121 & $\mathrm{AIC}$ & -82.77121 & \\
\hline & Regress $R^{2}$ & 0.9913 & Total $\mathrm{R}^{2}$ & 0.9856 & \\
\hline & Durbin-Watson & 1.5797 & $\operatorname{Pr}<\mathrm{DW}^{\mathrm{z}}$ & 0.0860 & \\
\hline & & & $\operatorname{Pr}>\mathrm{DW}^{\mathrm{z}}$ & 0.9140 & \\
\hline Variable & df & Parameter estimate & SE & t value & $\operatorname{Pr}>|t|$ \\
\hline Intercept & 1 & 5.2593 & 0.1819 & 28.91 & $<0.0001$ \\
\hline $\ln \left(\mathrm{PR}^{\mathrm{P}}\right)$ & 1 & -0.001901 & 0.000718 & -2.65 & 0.0129 \\
\hline SQRT(PROMR PR-1 $)$ & 1 & 0.000564 & 0.000186 & 3.03 & 0.0051 \\
\hline $\ln (\mathrm{AV})$ & 1 & 0.9847 & 0.0247 & 39.93 & $<0.0001$ \\
\hline STRUC & 1 & 0.4095 & 0.0556 & 7.36 & $<0.0001$ \\
\hline
\end{tabular}

${ }^{\mathrm{z}}$ Note: $\operatorname{Pr}<\mathrm{DW}$ is the $P$ value for testing positive autocorrelation, and $\operatorname{Pr}>\mathrm{DW}$ is the $P$ value for testing negative autocorrelation.

Table 2. Models 2 and 3 seemingly unrelated regression results.

\begin{tabular}{|c|c|c|c|c|c|}
\hline \multicolumn{6}{|c|}{ Model 2: Texas sales of improved variety pecans } \\
\hline \multicolumn{6}{|c|}{ Dependent variable - $\ln \left(\mathrm{Y}^{\mathrm{i}}\right)$ (natural $\log$ of improved variety pecan sales) } \\
\hline Variable & df & Parameter estimate & SE & t value & $\operatorname{Pr}>|\mathrm{t}|$ \\
\hline Intercept & 1 & 3.891423 & 1.174182 & 3.31 & 0.0025 \\
\hline $\ln \left(\mathrm{PR}^{\mathrm{i}}\right)$ & 1 & -0.32312 & 0.140502 & -2.30 & 0.0291 \\
\hline SQRT(PROM $\left.{ }_{t-1}\right)$ & 1 & 0.000801 & 0.000396 & 2.02 & 0.0531 \\
\hline $\ln \left(\mathrm{Y}_{\mathrm{t}-1}^{\mathrm{i}}\right)$ & 1 & 0.392642 & 0.051400 & 7.64 & $<0.0001$ \\
\hline $\ln (\mathrm{AV})$ & 1 & 0.646930 & 0.079014 & 8.19 & $<0.0001$ \\
\hline STRUC & 1 & 0.68397 & 0.095997 & -7.12 & $<0.0001$ \\
\hline $\mathrm{AD}$ & 1 & -0.28401 & 0.131801 & -2.15 & 0.0399 \\
\hline \multicolumn{3}{|c|}{ Durbin-Watson } & 2.51789 & & \\
\hline \multicolumn{3}{|c|}{ Number of observations } & 35 & & \\
\hline \multicolumn{3}{|c|}{ First-order autocorrelation } & -0.29533 & & \\
\hline \multicolumn{6}{|c|}{ Model 3: Texas sales of native variety pecans } \\
\hline \multicolumn{6}{|c|}{ Dependent variable $-\mathrm{Y}^{\mathrm{n}}$ (sales of native variety pecans) } \\
\hline Variable & df & Parameter estimate & SE & $\mathrm{t}$ value & $\operatorname{Pr}>|t|$ \\
\hline Intercept & 1 & 2.218923 & 0.988572 & 2.24 & 0.0323 \\
\hline $\ln \left(\mathrm{PR}^{\mathrm{i}}\right)$ & 1 & 0.103086 & 0.118872 & 0.87 & 0.3927 \\
\hline SQRT $\left(\right.$ PROM $\left._{t-1}\right)$ & 1 & 0.000163 & 0.000492 & 0.33 & 0.7423 \\
\hline $\ln \left(\mathrm{Y}_{\mathrm{t}-1}^{\mathrm{i}}\right)$ & 1 & -0.08370 & 0.049658 & -1.69 & 0.1023 \\
\hline \multirow[t]{7}{*}{$\ln (\mathrm{AV})$} & 1 & 1.411479 & 0.100765 & 13.01 & $<0.0001$ \\
\hline & Durt & atson & 1.831096 & & \\
\hline & Num & f observations & 35 & & \\
\hline & First & autocorrelation & -0.29533 & & \\
\hline & & System stati & & & \\
\hline & Syst & eighted MSE & 1.0012 & & \\
\hline & Syst & eighted $R^{2}$ & 0.9714 & & \\
\hline
\end{tabular}

The most interesting result is the significance of the promotion variable at the $10 \%$ level $(P=0.0531)$ in Model 2 (improved variety pecan sales) and the insignificance of the promotion variable in Model 3 (native pecan sales). These results provide evidence in favor of the hypothesis that promotion has had a positive impact on sales of improved varieties and little or no statistically measurable effects on the sales of native pecans. The short-run promotion elasticity of improved variety sales was calculated to be 0.04422 with a long-run elasticity of 0.07285 .

Availability was also found to be a highly significant $(<0.0001)$ determinant of the sales of both improved and native varieties of pecans. Thus, perhaps the most important determinant of pecan sales in most years is yield variation, which constrains the availability of pecans for sale in some years and allows greater market responsiveness in other years.
As discussed earlier, native varieties are more susceptible to year-to-year yield fluctuations than improved varieties. Thus, the estimated coefficient for the availability of pecans for native/seedling varieties (1.4114) is more than double that for improved varieties (0.6469).

The lagged dependent variables in Models 2 and 3 were also found to be statistically significant at the $1 \%$ and $10 \%$ levels, respectively. The positive estimated coefficient for the lagged sales of improved pecan varieties and the negative estimated coefficient for lagged sales of native pecans in their respective models reflect the trend by buyers toward improved varieties and away from native pecans.

\section{Benefit-cost Analysis}

Although the Texas Pecan Promotion Program over the last 8 years has effectively 
increased Texas sales of improved pecan varieties, the critical question is whether the cost of achieving the increase has been less than the revenues generated by the increased sales. In other words, whether the promotion program can be judged to be "effective" depends not only on whether sales have been enhanced by the program, but whether and how much return on their investment contributors to the program have received. To explore this question, the statistical results were used to calculate both a NBCR and a DBCR as measures of the cost-effectiveness of the promotion program (see Williams et al., 2008, for procedures and formulas). In general, if the calculated BCR is greater than one, the promotion program is deemed "effective" because more than $\$ 1$ in sales revenue is generated for every dollar spent in promotion. On the other hand, if the calculated BCR is less than one, the program is deemed "ineffective."

The NBCR for the Texas Pecan Promotion Program over the 8-year period of 1999 2000 through $2006-2007$ is calculated to be 35.0 to 1 meaning that for every dollar spent by the Texas Pecan Board on promotion of pecan sales, the return was $\$ 35.0$ in additional Texas dollar sales of pecans (Table 3 ). Given the finding that promotion activities have had no statistically significant effect on Texas sales of native pecans, the $\$ 35.0$ return was all from additional sales of improved varieties. The SBCR provides a measure of sales volume impact per dollar spent. Calculated at 26.4, the SBCR suggests TPB has generated an average of $26.4 \mathrm{lbs}$ in additional sales of improved pecan varieties for every dollar spent on promotion.

\section{Conclusions and Implications for State-level Pecan Promotion Programs}

Pecan promotion and advertising at the state level can be effective in increasing state sales of pecans. We find that the promotional expenditures by the Texas Pecan Board, and funded by the Texas Pecan Checkoff Program since its inception in 1998, have been effective in augmenting Texas pecan sales. With respect to the three key questions of focus, the specific findings of this study are the following:

Texas Pecan Board Pecan promotion expenditures have effectively increased the demand for Texas pecans and, thus, the quantity of total pecans sold over the 8-year period of 1999-2000 through 2006-2007. Promotion expenditures since the inception of the Texas Pecan Checkoff Program have added an average of nearly 2.7 million $1 \mathrm{bs}$ annually to Texas pecan sales for a total of 21.5 million lbs ( $4.9 \%$ of actual sales) from 1999-2000 through 2006-2007 that would have not been sold without the promotion program. In terms of industry revenue, the promotion program added an average of nearly $\$ 3.7$ million annually for a total of over \$29.4 million in additional sales of pecans over the period.

Sales of improved varieties of pecans have been the main beneficiary of the promotion program. The promotion-led increase in sales experienced by the Texas pecan industry has been composed primarily of improved variety pecans rather than native pecans. Promotion expenditures of the Texas Pecan Board were found to have a statistically significant effect on Texas sales of improved pecans such that a doubling of expenditures would result in a $4.2 \%$ increase in sales of improved pecans in the next period. This result is consistent with the estimated effects of promotion on sales of other checkoff commodities reported in the literature. In contrast, promotion expenditures were found to have no statistically discernible effect on sales of native pecans. Since its inception, the Texas Pecan Board has focused on increasing the visibility of pecans for home consumption and, by doing so, may have unintentionally promoted sales of improved varieties of pecans rather than sales of native pecans because improved varieties tend to be used for home consumption, whereas native pecans tend to be used for food and candy production.

Table 3. Benefit-cost analysis of Texas pecan promotion, 1999-2000 to 2006-2007. ${ }^{2}$

\begin{tabular}{|c|c|c|}
\hline & Improved varieties & Native varieties $^{y}$ \\
\hline \multicolumn{3}{|l|}{ Additional sales (lbs) } \\
\hline Crop year average & $2,691,815.4$ & - \\
\hline Eight-year total & $21,534,522.9$ & - \\
\hline Average nominal price $(\$ / 1 \mathrm{~b})$ & 1.31 & \\
\hline \multicolumn{3}{|l|}{ Additional revenue (\$) } \\
\hline Crop year average & $3,675,119.3$ & - \\
\hline Eight-year total & $29,400,954.4$ & - \\
\hline \multicolumn{3}{|l|}{ Promotion expenditures $(\$)$} \\
\hline Crop year average & $101,976.6$ & - \\
\hline Eight-year total expenditures & $815,813.1$ & - \\
\hline Revenue BCR (RBCR) $(\$ / \$)$ & 36.0 & - \\
\hline Net revenue BCR $(\$ / \$)$ & 35.0 & - \\
\hline Discounted BCR $(\$ / \$)^{x}$ & 30.5 & - \\
\hline Sales BCR (lbs/\$) & 26.4 & - \\
\hline
\end{tabular}

Texas Pecan Board pecan promotion programs have generated a net revenue to the industry of $\$ 35$ for every pecan checkoff dollar spent on promotion or $\$ 30.5$ on a discounted, present value basis. In terms of sales, the promotion programs have generated $26.4 \mathrm{lbs}$ in additional sales of improved varieties of pecans per dollar spent on promotion.

These results imply that even with a limited budget, state-level efforts to promote pecans can successfully boost state pecan sales and provide a positive return to contributors. The results also provide other important insights for state-level pecan promotion programs:

State-level pecan promotion programs are likely greatly underfunded. The BCR calculated for the Texas Pecan Promotion Program seems high relative to those generally reported for the larger commodity promotion programs. Reported BCRs for commodity checkoff programs typically range from $\approx 2: 1$ to $10: 1$, although much higher BCRs (from 12:1 up to 50:1 and higher) are not uncommon (Williams and Capps, 2006). Given the low level of pecan promotion expenditures by Texas (and most other pecan-producing states) compared with that of the major checkoff commodities like cotton, soybeans, beef, and pork, the somewhat higher BCR found for Texas pecans is not unreasonable and likely not much different from those of other state-level pecan promotion programs. A high BCR simply means that a state-level pecan promotion like that of Texas is highly underfunded. Both experience and the theory of advertising suggest strongly that a substantial increase in funding over time would likely reduce the high BCR to state-level promotion programs to levels more in line with those of the betterfunded commodity promotion programs.

Free riders can seriously limit the impact of a state-level promotion program. In Texas, only $\approx 44 \%$ of the total potential pecan assessment is collected on average each year (Adams, 2007). Thus, for Texas and other states with little or no enforcement of the checkoff collection and payment requirements, a potentially large portion of the additional industry revenues generated by the pecan promotion program is earned by those who have chosen not to contribute to the cost of promotion. Unfortunately, for states like Texas with low assessment rates, a significant portion of the annual collections or a substantial increase in the assessment rate would be required just to pay the cost of a collections program. The implication is that although a low assessment rate can generate additional industry revenues, it also may allow free riders to enjoy the benefits of the program without being required to pay the cost.

Allocating state-level pecan checkoff funds away from promotion of sales for home consumption to the promotion of industrial uses might reduce overall returns from pecan promotion. Like Texas, pecan promotion programs of other states may focus on sales of pecans for home consumption and, therefore, may be unintentionally promoting 
sales of improved over native varieties of pecans. A more balanced allocation of promotion funds that includes industrial uses of pecans (food and candy production) might allow some impact on sales of native varieties. However, such a reallocation of limited promotion budgets could well reduce the overall return from promotion particularly if improved variety sales are more responsive to promotion efforts than sales of native varieties as is the case in Texas.

A high benefit-cost ratio does not imply a large impact of the program on sales. A high estimated pecan promotion BCR, as found in this study for one state-level pecan promotion program, should not be mistaken to imply large absolute impacts of pecan promotion programs on pecan sales. A BCR of $35: 1$, as found for the Texas pecan promotion program, can be calculated from dividing a $\$ 35$ billion industry profit benefit by a $\$ 1$ billion checkoff investment or by dividing a $\$ 35$ benefit by a $\$ 1$ investment. Actual expenditures on state-level pecan promotion activities are quite small in comparison with the total value of state pecan sales. With such a low level of investment compared with sales, the overall impact of a statelevel pecan promotion program like that of Texas could hardly be expected to be significant in a practical sense in its effects on sales, although the impact was found to be statistically significant. For Texas, results of this study imply that the pecan promotion program can take credit for no more than $\approx 5 \%$ of total pecan sales since the beginning of the program. Although seemingly small, this level of impact is quite large given the small amount of funds available for promotion. The danger is that, in its efforts to encourage compliance with the assessment requirement or to sell the program during a referendum, a state pecan promotion group like the Texas Pecan Board could communicate that a high promotion BCR means that the promotion program has been a major factor influencing state pecan sales. This misinterpretation of the $\mathrm{BCR}$ is a common occurrence among commodity checkoff programs and leads contributors to expect large impacts on their sales and revenues (Williams and Capps, 2006). When such impacts do not occur, support for the program among contributors begins to wane. A more prudent message to contributors is that the per-unit return is large but on a very few dollars available for investment, implying the need for more investment for more meaningful returns. At the same time, the promotion program could be better sold to contributors as producer-controlled tools that pay more than they cost to help reduce downside pressure on sales in bad years and contribute to sales in good years rather than as a panacea to the financial problems they face.

Not all contributors receive the same benefits. The positive BCR calculated for the pecan promotion program indicates that contributors gain "on average" from the program. Chung and Kaiser (2000) point out, however, that the benefits of a checkoff program may not be evenly distributed among contributors with some gaining more than others. They conclude that more of the total benefits accrue to larger producers, although smaller producers benefit more in terms of the net revenues accrued per unit of assessed checkoff. If smaller producers tend to be higher-cost producers and large producers tend to be lower-cost producers, then Chung and Kaiser's results suggest that highcost producers benefit the most and low-cost producers benefit the least. That is, those that pay the most receive the least per dollar that they pay in checkoff assessment. Thus, a checkoff program may work as a mechanism to redistribute income from large, lowcost producers to small, high-cost producers. If this is the case and the differences in benefits are substantial, larger producers may begin to feel somewhat disenfranchised over time and to be less supportive of the checkoff program. Several checkoff programs (for example, beef and cotton) have experienced these problems, which has led to protracted court cases related to the mandatory nature of the programs.

\section{Literature Cited}

Adams, B.M. 2007. Texas pecan checkoff 2007 annual report. TX Pecan Growers Assn. Conf. 17 July. Corpus Christi, TX.

Almon, S. 1965. The distributed lag between capital appropriations and expenditures. Econometrica 33:178-195.

Alston, J.M., H.F. Carman, J. Christian, J. Dorfman, J.-R. Murua, and R. Sexton. 1995. Optimal reserve and export policies for the California almond industry: Theory, econometrics, and simulations. Giannini Found. Monogr. 42. Giannini Foundation Agr. Econ., Univ. CA, Davis, CA.

Becker, G.S. 2004. Federal farm promotion ("check-off") programs. CRS Rpt. Congr. No. 95-353 ENR. Congr. Res. Serv., The Library of Congress, Washington, DC, Mar. 25.

Bushnell, P.G. and G. King. 1986. The domestic and export markets for California Almonds. Giannini Found. Res. Rpt. 334. Giannini Foundation of Agr. Econ., University of California, Davis, CA. Chung, C. and H.M. Kaiser. 2000. Do farmers get an equal bang for their buck from generic advertising programs? A theoretical and empirical analysis. J. Agr. Resource Econ. 20:147-158.

Crespi, J.M. and R.J. Sexton. 2001. Almond advertising yields net benefits to growers. CA. Agr. 55:20-25.

Erickson, M.C. 1994. Methods for measurement of pecan quality. In: Santerre, C.R. (ed.). Pecan technology. Chapman \& Hall, New York, NY.

Florkowski, W.J. and E.E. Hubbard. 1994. Structure and performance of the pecan market. In: Santerre, C.R. (ed.). Pecan technology. Chapman \& Hall, New York, NY.

Florkowski, W.J. and T.A. Park. 2001. Promotion programmmes and consumer purchasing decisions: Pecan demand models. Appl. Econ. 33:763-770.

Florkowski, W.J., J.C. Purcell, and E.E. Hubbard. 1992. Importance for the United States pecan industry of communicating about quality. HortScience 27:462-464.

Florkowski, W.J. and X.-L. Wu. 1990. Simulating impact of pecan storage technology on farm price and growers' income. Southern J. Agr. Econ. 22:217-222.
Halliburton, K. and S. Henneberry. 1995. The effectiveness of U.S. nonprice promotion of almonds in the Pacific Rim. J. Agr. Resource Econ. 20:108.

Kinnucan, H.W. and J.E. Christian. 1997. A method for measuring returns to nonprice export promotion with application to almonds. J. Agr. Resource Econ. 22:120-132.

Kinnucan, H.W., Y. Miao, H. Xiao, and H.M. Kaiser. 2001. Effects of advertising on U.S. non-alcoholic beverage demand: Evidence from a two-stage rotterdam model, p. 1-30. In: Baye, M.R. and J.P. Nelson (eds.). Advances in applied microeconomics: Advertising and differentiated products. Vol. 10. Elsevier Science Ltd., Oxford, UK.

Onunkwo, I.M. and J. Epperson. 2000. Export demand for U.S. pecans: Impacts of U.S. export promotion programs. Agribusiness 16:253-265.

Park, T.A. and W.J. Florkowski. 1999. Demand and quality uncertainty in pecan purchasing decisions. J. Agr. Appl. Econ. 31:29-39.

Pindyck, R.S. and D.L. Rubinfeld. 1998. Economic models and economic forecasts. McGraw Hill, New York, NY.

Rajaram, S., K. Burke, B. Connell, T. Myint, and J. Sabaté. 2001. A monounsaturated fatty acidrich pecan-enriched diet favorably alters the serum lipid profile of healthy men and women. J. Nutr. 131:2275-2279.

Rusmevichientong, P. and H.M. Kaiser. 2009. Measuring the effectiveness of U.S. rice export promotion programs. Agribusiness Intl. J. 25: 215-230.

Shafer, C. 1996. Pecan production and price trends 1979-1995. Texas A\&M University System, Texas Agr. Expt. Sta., Dept. Agr. Econ., Faculty Paper 96-03.

Thompson, T.E. and F. Young. 1985. Pecan cultivarsPast and present. Texas Pecan Growers Assn., College Station, TX.

U.S. Department of Agriculture. 2008a. Crop production. Natl. Agr. Stat. Serv., Washington, DC. 5 June 2009. <http://www.nass.usda.gov/ QuickStats/index2.jsp>.

U.S. Department of Agriculture. 2008b. Fruit and tree nut yearbook. Econ. Res. Serv., Washington, DC. 5 June 2009. <http://usda.mannlib. cornell.edu/MannUsda/viewDocumentInfo.do? documentID=1377>.

U.S. Department of Commerce. (2008). National Economic Accounts. Bureau Econ. Analysis, Washington, DC. 5 June 2009. <http://www.bea. gov/national/index.htm>.

Williams, G.W. 1999. Commodity checkoff programs as alternative producer investment opportunities: the case of soybeans. Agribusiness 15:539-552.

Williams, G.W. and O. Capps, Jr. 2006. Measuring the effectiveness of checkoff programs. Choices 21:73-78.

Williams, G.W., O. Capps, Jr., and D.A. Bessler. 2004. Florida orange grower returns from orange juice advertising. (Texas Agribusiness Market Research Center Consumer and Product Research Report No. CP-01-04). Texas A\&M University, Department of Agricultural Economics, College Station, TX. February.

Williams, G.W., O. Capps, Jr., and M.A. Palma. 2008. Effectiveness of marketing promotion programs: The case of Texas citrus. HortScience 43:385-392.

Wood, B.W., J.A. Payne, and L.J. Grauke. 1994. An overview of the evolution of the U.S. pecan industry. In: Santerre, C.R. (ed.). Pecan technology. Chapman \& Hall, New York, NY.

Worley, R. 1994. Pecan production. In: Santerre, C.R. (ed.). Pecan technology. Chapman \& Hall, New York, NY. 